\title{
ORganizaÇão eSTRUTURAL E ULTRA-ESTRUTURAL DAS CÉLULAS VEGETATIVAS E DA ESTRUTURA PLURILOCULAR DE Hincksia mitchelliae (Harvey) P. C. Silva (Ectocarpales, Phaeophyceae)
}

Luciane C. Ouriques ${ }^{1}$ \& Zenilda L. Bouzon

\begin{abstract}
Resumo
(Organização estrutural e ultra-estrutural das células vegetativas e da estrutura plurilocular de Hincksia mitchelliae (Harvey) P. C. Silva (Ectocarpales, Phaeophyceae) O presente estudo tem por objetivo contribuir para o estudo de caracteres sub-celulares que poderão ser utilizados na taxonomia das Phaeophyceae filamentosas, fornecendo dados sobre a estrutura e ultra-estrutura das células vegetativas e do estágio reprodutivo plurilocular de H. mitchelliae. Para tanto, estudos de microscopia de luz e eletrônica de transmissão foram realizados. As células vegetativas e reprodutivas de H. mitchelliae são uninucleadas, revestidas por uma parede celulósica, outros polissacarídeos e proteínas. A presença de um núcleo por célula, a organização dos tilacóides nos cloroplastos, formando bandas com três tilacóides, dispostos longitudinalmente ao eixo maior da organela e ausência de tilacóide no pirenóide foram similares a outras Phaeophyceae. H. mitchelliae também exibiu características ultra-estruturais que estão geralmente associadas a outras espécies, de ordens menos avançadas de Phaeophyceae como a presença de um proeminente pirenóide, dictiossomos perinucleares e plasmodesmos. A morfologia e a organização dos cloroplastos, bem como a presença ou ausência de pirenóide são características importantes dentro das Phaeophyceae. A formação de um novo pirenóide, em estágio de diferenciação, foi observada nos cloroplastos das células vegetativas. Ambas as células apresentaram núcleo com um grande nucléolo, sugerindo uma alta atividade metabólica. Muitos corpos osmiofílicos, os fisóides, foram vistos no citoplasma das células vegetativas e reprodutivas. As células da estrutura plurilocular madura de $H$. mitchelliae diferiram das células vegetativas por apresentar tamanho reduzido, citoplasma denso e desprovidas de vacúolos.
\end{abstract}

Palavras-chave: Hincksia mitchelliae, organização estrutural e ultra-estrutural.

\section{Abstract}

(Structural and ultrastructural organization of the vegetative cells and plurilocular structure of Hincksia mitchlelliae (Harvey) P. C. Silva (Ectocarpales, Phaeophyceae) This study aims to contribute to the suty of sub-cellular characters that may be used in the taxonomy of filamentous Phaeophyceae. Studies of light and electron microscopy transmission provided data on the structure and ultrastructure of the cells in the vegetative stage and plurilocular reproductive structures of $H$. mitchelliae. Vegetative and reproductive cells of $H$. mitchelliae are uni-nucleated, coated with a cellulose wall, other polysaccharides and proteins. The presence of a single nucleus, organization of thylakoids in the chloroplasts forming three thylakoids per band, longitudinally arranged at the major axis of the organelles, and absence of thylakoids in the pyrenoid are similar to those of other Phaeophyceae. H mitchelliae also exhibits ultrastructural characteristics that are generally associated with other species from less advanced orders of Phaeophyceae: the presence of a prominent pyrenoid, perinuclear dictyosomes and plasmodesmatas. The morphology and the organization of chloroplasts as well the presence or absence of pyrenoid are important features in the Phaeophyceae. The formation of a new pyrenoid during differentiation periods was observed in chloroplasts of vegetative cells. Both cells presented a nucleus with a large nucleolus, suggesting an intense metabolic activity. Many osmiophilic bodies called physodes were observed in the cytoplasm of the vegetative and reproductive cells. Cells of matured plurilocular structure of $H$. mitchelliae differed from vegetative cells due to its reduced size, dense cytoplasm, and absence of vacuoles.

Key words: Hincksia mitchelliae, structural organization and ultrastructure.

Artigo recebido em 10/2007. Aceito para publicação em 06/2008.

${ }^{1}$ Universidade Federal de Santa Catarina, Centro de Ciências Biológicas, Departamento de Biologia Celular, Embriologia e Genética, Campus Universitário, Trindade, 88040-900 Florianópolis, SC, Brasil. ouriques@ @cb.ufsc.br 


\section{INTRODUÇÃO}

Os membros da classe Phaeophyceae são classificados em diferentes ordens de acordo com a organização do talo, tipo de crescimento, tipo de reprodução sexuada, padrão de histórico de vida e organização dos cloroplastos (Bold \& Wynne 1985). Os membros desta ordem apresentam os talos formados por tufos frouxos com filamentos unisseriados ramificados, organização heterotríquia, nunca unidos em um tecido pseudoparenquimatoso. $\mathrm{O}$ crescimento do talo é do tipo difuso. $\mathrm{O}$ ciclo de vida é diplobionte e isomórfico e a sexualidade é isogâmica ou anisogâmica (Rousseau \& Reviers 1999). Entre as algas pardas, as estruturas reprodutivas podem ser denominadas de 'órgãos' pluriloculares e uniloculares. As células produzidas na estrutura plurilocular são móveis e derivadas de mitose. A estrutura plurilocular pode ocorrer tanto no gametófito quanto no esporófito, enquanto que a estrutura unilocular ocorre apenas no esporófito e é o centro da meiose (Bold \& Wynne 1985; van Den Hoek et al 1995). Dentro da ordem Ectocarpales, Hincksia mitchelliae (Harvey) P.C. Silva é uma espécie amplamente distribuída em mares tropicais, subtropicais e temperados (van den Hoek et al. 1995; Ouriques \& CordeiroMarino 2004; Wynne 2005). Cresce na região entre marés sobre rochas, molusco (Perna perna Linnaeus), craca (Tetraclita stalactifera Lamarck), gastrópode (Fissurela sp.) e também sobre algumas algas maiores (Ouriques \& Cordeiro-Marino 2004).

A ultra-estrutura das células vegetativas tem sido utilizada para distinguir não somente as Phaeophyceae de outras algas, mas também ordens menos avançadas das mais avançadas, dentro da classe (ex. Cole 1970; Galatis et al. 1977).

A parede celular das Phaeophyceae é composta por microfibrilas de celulose, dois principais polissacarídeos ácidos (alginato e fucoidina), várias proteínas e compostos fenólicos (Lee 1989, van den Hoek et al. 1995, Schoenwaelder 2002, Salgado et al. 2007). Nos vegetais a formação da parede celular é acompanhada com o marcador para celulose, o calcofluor white, corante fluorescente que tem sido introduzido para a identificação de material da parede celular de diferentes espécies de plantas inclusive algas. Esse corante reage especificamente com polissacarídeos fibrilares, e.g. celulose (Sengbusch et al. 1982, Sengbusch \& Müller 1983).

As Phaeophyceae apresentam cloroplastos geralmente de forma discóide com tilacóides arranjados em grupos de três, formando uma banda, e o conjunto de bandas é envolvido por uma banda periférica circular (Lee 1989, van den Hoek et al. 1995).

As células das Phaeophyceae são uninucleadas e o material nuclear (DNA) tem sido estudado em preparações histológicas com o uso do corante fluorescente, o fluorocromo 4'6-diamidino-2-phenylindole (DAPI). Com a utilização desse corante foi possível mostrar a ocorrência de uma divisão coordenada entre o núcleo e o cloroplasto durante o processo de formação de unisporos, no esporângio unilocular de Laminaria angustata Kjellmann (Motomura et al. 1997).

A análise ultra-estrutural das células reprodutivas das Phaeophyceae evidencia as alterações sub-celulares durante o processo de desenvolvimento dos zoósporos no esporângio unilocular antes do amadurecimento celular (Markey \& Wilce 1976a; Katsaros \& Galatis 1986). As características ultra-estruturais da tetrasporogênese de Dictyota dichotoma (Hudson) Lamouroux evidenciaram que algumas células epidérmicas podem se diferenciar em células mãe do tetrasporângio (Katsaros \& Pentaris 1994). Essas células apresentam intensa atividade metabólica, expressa pelo citoplasma denso e numerosos vacúolos pequenos. As diferenças estruturais e funcionais entre os gametas masculino e feminino de Scytosiphon sp. foram caracterizadas, especialmente pela presença de um tipo de vesícula derivada do complexo de Golgi, específica no gameta feminino (Clayton 1984). Os estudos sobre à ultra-estrutura da estrutura reprodutiva das Phaeophyceae filamentosas são escassos. Esses incluem a ultra-estrutura 
da mitose e citocinese no gametângio plurilocular de Pylaiella littoralis (L.) Kjellm. (Markey \& Wilce 1975), e a ultra-estrutura da formação do esporângio unilocular de Ectocarpus sp. (Baker \& Evans 1973) e do gametângio plurilocular de $P$. littoralis (Markey $\&$ Wilce 1976b).

Com os resultados deste estudo busca-se contribuir com informações adicionais a respeito de caracteres morfológicos subcelulares que poderão ser utilizados na taxonomia das Phaeophyceae filamentosas, fornecendo dados relativos àestrutura e ultraestrutura das células vegetativas e do estágio reprodutivo plurilocular de $H$. mitchelliae.

\section{Material e Métodos}

H. mitchelliae foi coletada no mesolitoral, na praia da Lagoinha, Ilha de Santa Catarina, Florianópolis, SC. As coletas foram feitas durante as marés baixas, na região entre marés, com auxílio de espátula; em seguida, as amostras foram acondicionadas em sacos plásticos e triadas no laboratório. Para a observação da parede celular, as porções vegetativas e reprodutivas foram fixadas em solução de paraformaldeído $2,5 \%$, em tampão fosfato $0,2 \mathrm{M}, \mathrm{pH} 7,2$, por aproximadamente $4-6 \mathrm{~h}$, à temperatura de $4^{\circ} \mathrm{C}$ e coradas com Calcofluor White M2R 10 mmg. $\mathrm{mL}^{-1}$ por $30 \mathrm{~min}$. Logo após, as amostras foram lavadas no mesmo tampão por $15 \mathrm{~min}$ (Kim \& Fritz 1993). No procedimento para a marcação do núcleo com o uso de DAPI, o material foi fixado em Carnoy's por aproximadamente 6h (Ruzin 1999) e, logo após, lavado em tampão Tris-(hidroximetil)-aminometano 0,2M, por $20 \mathrm{~min}$. Em seguida, as amostras foram colocadas em Triton-X-100 $(0,2 \%)$, por $40 \mathrm{~min}$ e corados com DAPI (4'6-diamidino-2-phenylindole) na concentração de $0,5 \mathrm{mmg} \mathrm{ml}^{-1}$ (Terui et al. 1995 modificado), por aproximadamente $50 \mathrm{~min}$. $\mathrm{O}$ material foi analisado e fotografado em microscópio fotônico modelo Olympus BH, equipado com câmara fotografica modelo Olympus C-35AD. As observações com o uso dos corantes fluorescentes foram feitas em microscópio Olympus BX 41 epifluorescente com o filtro de comprimento de onda U-MWB2 'excitação no azul', excitação em 360 nm e emissão 460If $\mathrm{nm}$, apropriado para DAPI e Calcofluor e fotografados com ISO 400.

Para observação em microscopia eletrônica de transmissão, as amostras foram fixadas em solução de glutaraldeído 2,5\%, paraformaldeído $2,0 \%$, cloreto de cálcio $\left(\mathrm{CaCl}_{2}\right) 5 \mathrm{mM}$, em tampão cacodilato de sódio $75 \mathrm{mM} \mathrm{e} \mathrm{pH} \mathrm{7,2,} \mathrm{por}$ aproximadamente $5 \mathrm{~h}$ a temperatura ambiente. A fixação foi seguida por 3 lavagens, de 30min cada, no mesmo tampão. Logo após, o material foi pós-fixado em tetróxido de ósmio a 2,0\%, ferrocianeto de potássio $\left[\mathrm{K}_{4} \mathrm{Fe}(\mathrm{CN})_{6} \cdot 3 \mathrm{H}_{2} \mathrm{O}\right]$ $0,8 \%$ e $5 \mathrm{mM}$ de $\mathrm{CaCl}_{2}$ por $2 \mathrm{~h}$. Após serem lavadas novamente no mesmo tampão, as amostras foram desidratadas em uma série crescente de acetona (30 min. em cada concentração), infiltradas em séries graduais de acetona-resina Spurr durante 3 dias, seguido de duas infiltrações em resina pura (12h) e polimerizadas em estufa a $70^{\circ} \mathrm{C}$ por $24 \mathrm{~h}$. Os cortes ultrafinos foram feitos com navalha de diamante em ultramicrotómo Porter-Blum, e posteriormente contrastados com acetato de uranila $1 \%$ e citrato de chumbo $1 \%$ (Bozzola $\&$ Russell 1992). Os cortes ultra-finos foram observados e fotografados no microscópio eletrônico de transmissão Zeiss EM 900.

\section{Resultados}

Hincksia mitchelliae apresenta organização filamentosa unisseriada com crescimento heterotríquio formando tufos. Os filamentos prostrados estão presos ao substrato por filamentos rizoidais compactos, dotados de células pouco pigmentadas (Fig. 1a). Os filamentos eretos são abundantes e ramificados de forma irregular (Fig. 1a), com células mais longas que largas com $30 \times 70 \mu \mathrm{m}$ (Fig. 1b). $\mathrm{O}$ crescimento do talo é do tipo difuso, com zonas meristemáticas de células curtas distribuídas ao longo dos filamentos eretos (Fig. 1a, e). Todas as células do talo quando tratados com Calcofluor White revelaram uma intensa fluorescência azul evidenciando o componente celulósico da parede celular (Fig. 1c). Observou-se que a parede celular entre as 


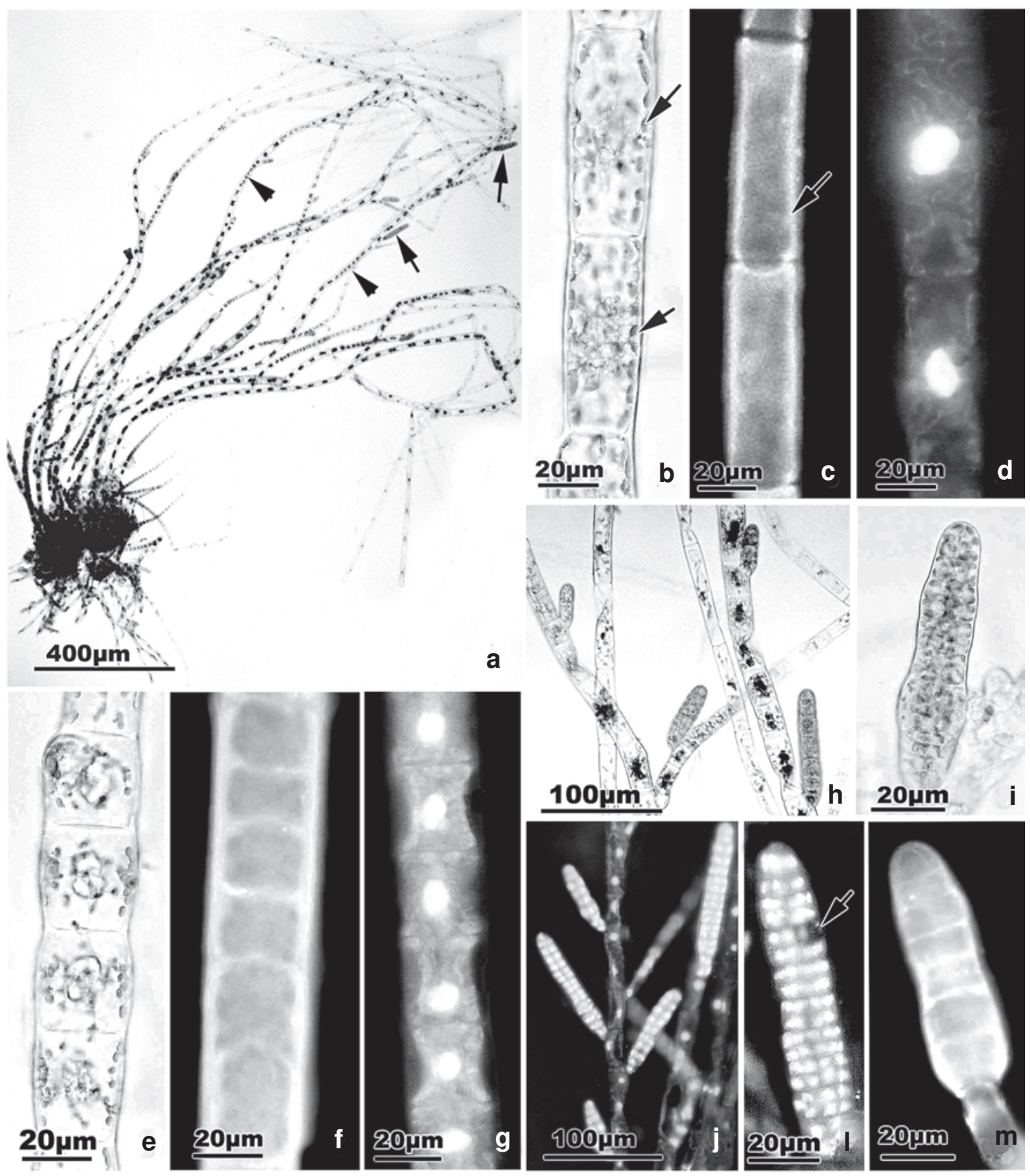

Figura 1 - Hincksia mitchelliae, microscopia de luz convencional e microscopia de fluorescência - a. aspecto geral da planta mostrando as células meristemáticas (cabeças de seta) e as estruturas pluriloculares (setas); b. detalhe das células vegetativas mostrando numerosos cloroplastos (setas); c. parede celular fluorescente com o uso de calcofluor (seta); d. células vegetativas tratadas com DAPI mostrando um só núcleo por célula; e. detalhe da região meristemática; f. região meristemática tratada com calcofluor; g. células meristemáticas coradas tratadas com DAPI mostrando um núcleo por célula; $h$. porção de um filamento ereto mostrando as estruturas pluriloculares nos ramos laterais; i. detalhe da estrutura plurilocular cilíndrico mostrando uma intensa pigmentação pela presença de numerosos cloroplastos; j. porção superior de filamento ereto mostrando as estruturas pluriloculares em diferentes estágios de maturação tratados com DAPI; 1. detalhe das estruturas pluriloculares com células uninucleadas indicadas pela reação positiva ao DAPI. Observe a presença de lócus vazios indicando a liberação de gametas (seta); m. estrutura plurilocular corado com calcofluor, mostrando uma parede mais espessa envolvendo toda a estrutura. 
células é mais delgada quando comparada à parede externa do filamento. Quando tratadas com DAPI as células vegetativas mostraram um único núcleo central, destacado pela reação positiva ao DNA(Fig. 1d). As células da região meristemática reagiram similarmente às outras regiões quando tratadas com DAPI e Calcofluor White (Fig. 1f-g). As células vegetativas apresentam cloroplastos discóides, individualizados, numerosos e distribuídos por todo o citoplasma periférico (Figs. 1b e 1e).

As estruturas pluriloculares são cilíndricas e distribuídas na parte interna dos ramos laterais (Figs. 1a, h). Dividem-se em vários lóculos constituídos por células cúbicas (Fig. 1i-1). Essas células são uninucleadas, indicado pela marcação com o uso de DAPI (Fig. 1j-1). Estruturas pluriloculares em diferentes estágios de maturação foram distinguidas pelo número de lóculos, evidenciado pelos núcleos marcados com DAPI (Fig. 1j). Uma delgada parede celular reveste cada célula que constituí a estrutura plurilocular, as quais foram marcadas com calcofluor evidenciando a composição celulósica (Fig. 1m).

As células vegetativas tanto em cortes transversais quanto em longitudinais apresentaram o citoplasma entrecortado por vacúolos, numerosos fisóides e cloroplastos (Fig. 2). Esses vacúolos são elétron-transparentes, de tamanhos variados, preenchem considerável porção do volume citoplasmático (Fig. 2). Nestas células, os dictiossomos estão distribuídos na região perinuclear e numerosas mitocôndrias são observadas próximos aos cloroplastos. As células são uninucleadas, com um núcleo interfásico grande com 4-6 $\mu \mathrm{m}$ de diâmetro, localizado na região central. Esses núcleos apresentam contorno irregular, e são limitados por uma dupla unidade de membrana

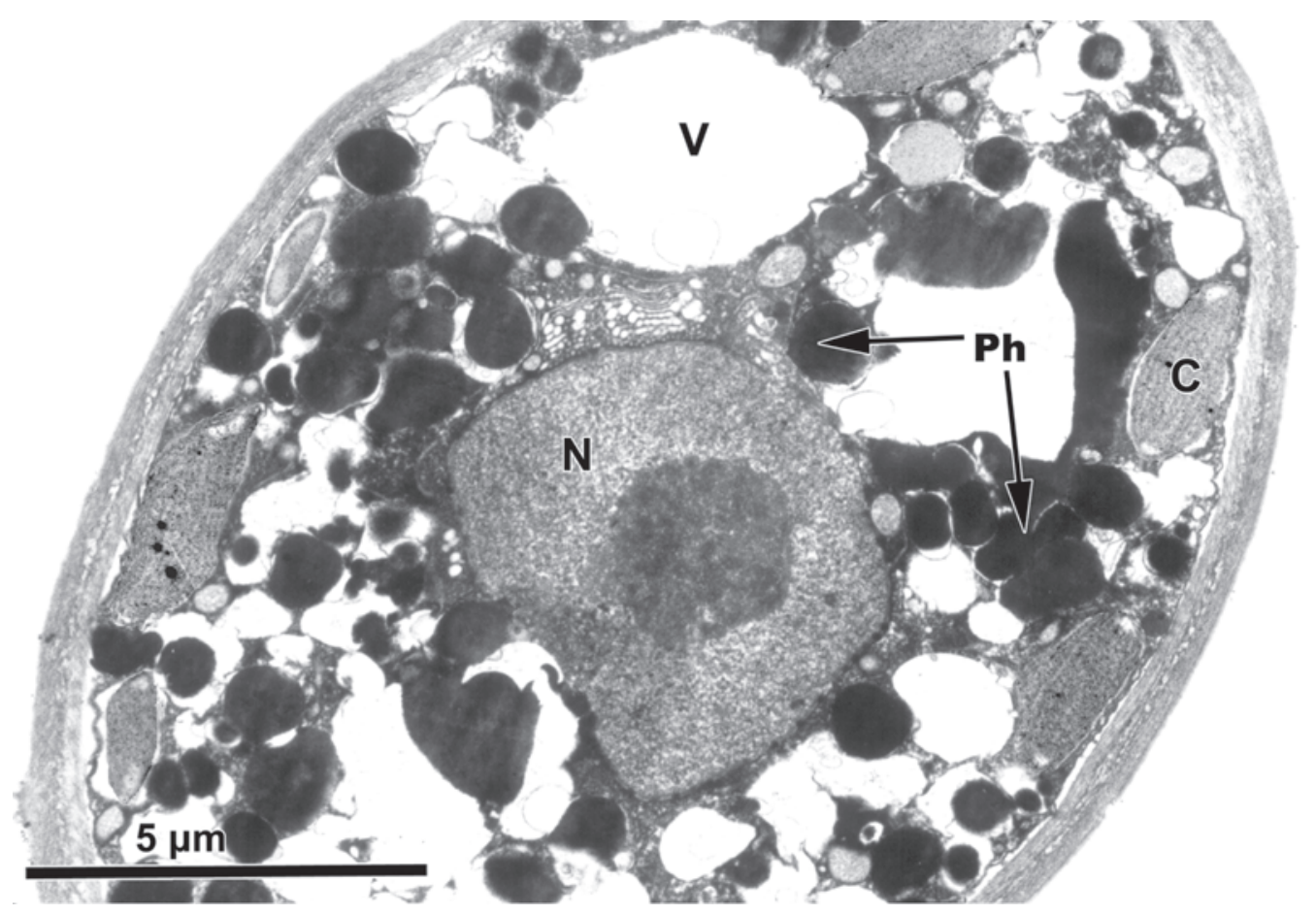

Figura 2 - Células vegetativas de Hincksia mitchelliae observadas no microscópio eletrônico de transmissão (MET) - corte transversal do talo mostrando o núcleo central $(\mathrm{N})$ com nucléolo proeminente. Os dictiossomos estão distribuídos na região perinuclear e os cloroplastos (C) no citoplasma periférico. Observe vacúolos (V) de tamanhos variados ocupando uma grande parte do volume celular e grânulos elétron-densos fisóides $(\mathrm{Ph})$. 
(Fig. 2). Nesses núcleos observou-se uma cromatina difusa, predominando a forma de eucromatina. Um grande nucléolo elétrondenso, medindo até $2 \mu \mathrm{m}$ de diâmetro, foi observado na maioria das células ocupando uma parte considerável do volume nuclear (Figs. 2 e 3a). O envelope nuclear aparentemente é interrompido por numerosos complexos de poros (Fig. 3b). A membrana externa do envelope nuclear está em íntima associação com os dictiossomos que se localizam na região perinuclear (Fig. 3a-b). Entre as cisternas da região de maturação dos dictiossomos e a membrana externa do envelope nuclear existe uma área de transição ocupada por pequenas vesículas que parecem brotar do envelope nuclear e se fundem na região de maturação dos dictiossomos. Como a face cis dos dictiossomos está voltada para a membrana externa do envelope nuclear, essas vesículas seriam incorporadas às cisternas em crescimento (Fig. 3b). Esses dictiossomos são constituídos por pilhas de 6-8 cisternas. As cisternas da face cis apresentam a região central mais delgada, sendo as extremidades dilatadas preenchidas por conteúdo elétrontransparente (Fig. 3b). Entretanto, as cisternas localizadas na região trans são uniformemente dilatadas (Fig. 3b).

A parede celular que delimita externamente o filamento é espessa e formada por agregados paralelos de microfibrilas de celulose que estão embebidos em uma matriz amorfa. Externamente, uma camada irregular de material mucilaginoso, cobre a parede (Fig. $3 c)$. As células são separadas umas das outras por uma parede delgada interrompida por pequenos canais, os plasmodesmos, que permitem a conexão dos citoplasmas das células adjacentes.

Os cloroplastos das células vegetativas são discóides e aparecem alongados em corte transversal, perifericamente distribuídos, ocupando uma parte significante do volume celular (Fig. 2). Cada cloroplasto é delimitado por uma dupla unidade de membrana preenchida por uma matriz densamente granular (Fig. 3d). Os tilacóides são agregados em bandas de três a três, uniformemente separadas por um espaço interbanda, exceto na região onde ocorrem alguns glóbulos elétron-densos, os plastiglóbulos (Fig. 3d). As bandas são distribuídas paralelamente ao eixo maior do cloroplasto. Estas bandas podem sofrer bifurcações resultando num aumento de tilacóides (Fig. 3d-e). O número de bandas é variável, pode-se observar até 11 bandas por cloroplasto. Em alguns cloroplastos, são identificáveis pequenas regiões elétrontransparentes, preenchidas por conteúdo fibrilar, nas extremidades dos tilacóides, as quais devem corresponder ao genoma plastidial. Na maioria dos cloroplastos verificou-se a presença de um pirenóide que se projeta a partir da região mediana formando uma grande saliência na superfície do cloroplasto. Ocasionalmente observa-se um segundo pirenóide localizado lateralmente ao pirenóide principal (Fig. 3d).

A estrutura plurilocular é formada por um aglomerado celular resultante de sucessivas divisões que ocorrem em vários planos, onde predominam as divisões transversais e oblíquas. No final da maturação dessa estrutura, as células resultantes caracterizam-se por um citoplasma denso devido à ausência de vacúolos, sendo preenchido por numerosas organelas (Fig. 4a). A parede celular com 2,0-3,0 $\mu \mathrm{m}$ de espessura, que reveste toda a estrutura plurilocular é formada por microfibrilas elétrondensas de aspecto compacto. As células são revestidas individualmente por uma fina parede com constituição semelhante a que reveste toda a estrutura (Fig. 4a). Nessas células, numerosas mitocôndrias aparecem distribuídas principalmente no citoplasma periférico, próximas aos cloroplastos (Fig. 4b). Os dictiossomos são perinucleares, como o observado nas células vegetativas, entretanto apresentam um número maior de cisternas que os torna hipertróficos (Figs. 4c e 4e). Essa hipertrofia é caracterizada especialmente pela presença de numerosas cisternas dilatadas com conteúdo elétron-transparente na região de 

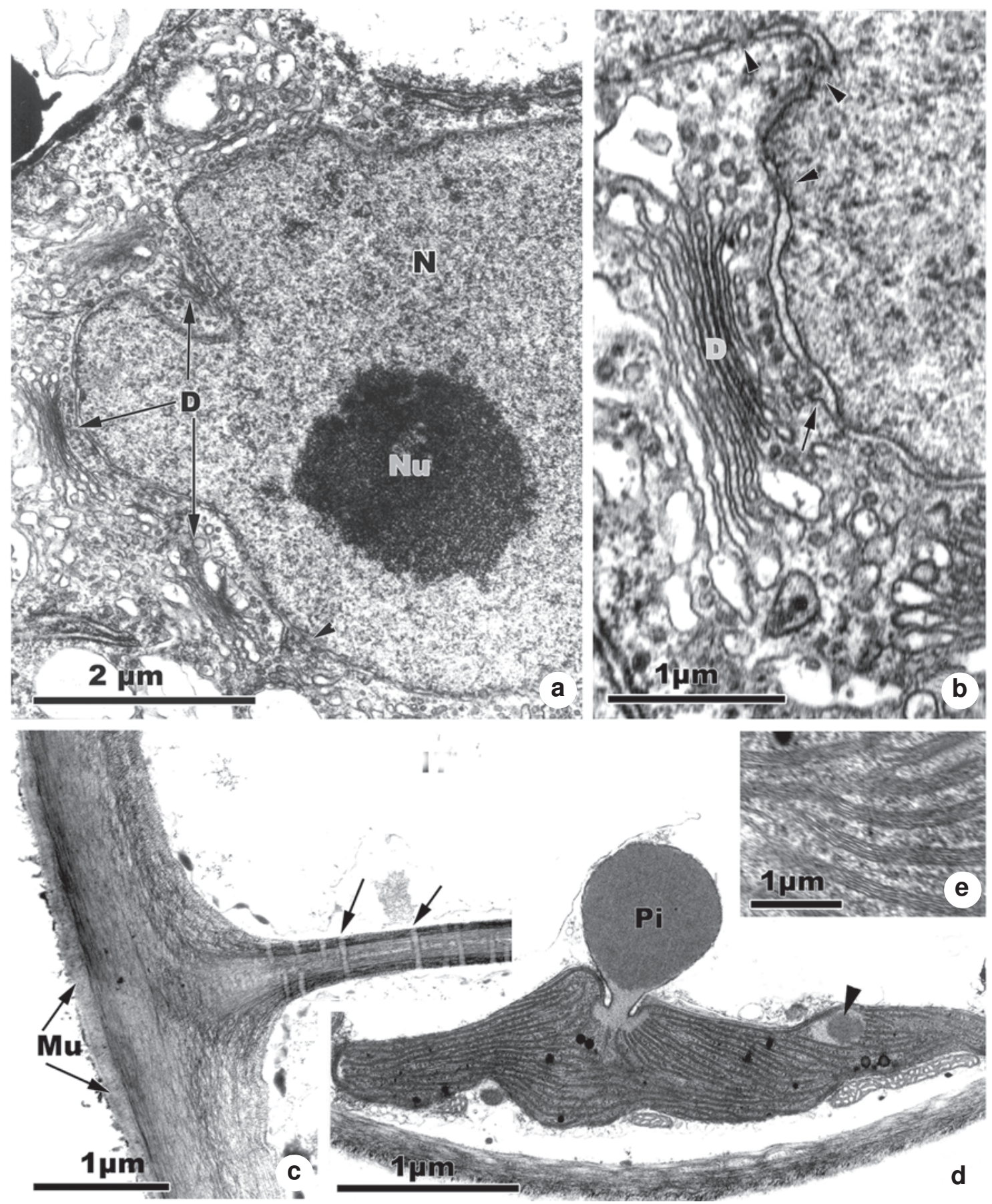

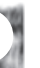


maturação (Fig. 4c). Os cloroplastos são numerosos, menores que nas células vegetativas e ocupam a maior parte do conteúdo citoplasmático. A organização membranar é semelhante a dos cloroplastos das células vegetativas onde as três bandas de tilacóides estão mergulhadas no estroma plastidial. Foram observadas 8-10 bandas paralelas de tilacóides por cloroplasto. $\mathrm{O}$ conjunto de bandas internas paralelas é envolvido por uma banda circular com organização semelhante às bandas internas. Uma unidade de membrana reveste todo o cloroplasto e o pirenóide que se projeta lateralmente (Fig. 4d).

As demais regiões do citoplasma são densamente preenchidas por ribossomos livres que conferem a essas regiões um aspecto granular (Fig. 4d). Os núcleos das células do órgão plurilocular são volumosos com até 10 $\mu \mathrm{m}$ diâmetro, apresentam cromatina bem difusa e grande nucléolo (Fig. 4e).

\section{Discussão}

A parede celular de $H$. mitchelliae apresenta microfibrililas de celulose evidenciadas pela reação ao Calcofluor White, como também observado em outras algas Phaeophyceae (e.g. Herth \& Schnepf 1980; Sengbusch et al. 1982).

Dentre as características ultra-estruturais observadas nas células vegetativas de $H$. mitchelliae, que são similares às descritas para as Phaeophyceae, destaca-se a presença de um núcleo por célula, a organização dos tilacóides nos cloroplastos, que são agrupados três a três, formando uma banda disposta longitudinalmente ao eixo maior da organela e ausência de tilacóide no pirenóide (Bouck 1965; Mccully 1968; Cole 1970; Galatis et al. 1977; Chung et al. 1987). Este padrão de organização dos cloroplastos pode apresentar pequenas variações como observado em $H$. mitchelliae, onde as bandas dos cloroplastos podem sofrer bifurcações resultando num aumento de tilacóides, similar ao observado em Laminaria saccharina (L.) Lamouroux (Chung et al. 1987).
A morfologia e a organização dos cloroplastos, bem como a presença ou ausência de pirenóide são consideradas características diagnósticas a serem empregadas na delimitação das ordens das Phaeophyceae (Hori 1972). Dentro das Phaeophyceae, os pirenóides estão presentes em certos membros das Ectocarpales, Chordariales, Scytosiphonales e Dictyosiphonales, consideradas mais primitivas, porém os mesmos estão ausentes em espécies de ordens mais derivadas (Griffiths 1979). Entre as Phaeophyceae que contêm pirenóides nos cloroplastos, são encontrados três tipos: um pirenóide que se projeta da região mediana do cloroplasto (Hori 1972), um pirenóide não projetado localizado na região central do cloroplasto (Delépine et al. 1976; Peter \& Clayton 1998) e pirenóides terminais (Delépine et al. 1976; Magne 1976; Müller \& Parodi 1994; Müller et al. 1998; Ouriques \& Bouzon 2000). Os cloroplastos de $H$. mitchelliae apresentam um pirenóide projetando-se a partir da região mediana, semelhante a muitas Phaeophyceae. Somente seis gêneros de Phaeophyceae filamentosas apresentam cloroplastos com aspecto estrelado (Peters \& Clayton 1998). Os gêneros Asterocladon Müller, Parodi \& Peters (Müller et al. 1998), Asteronema Delépine \& Asensi (Delépine et al. 1976; Müller \& Parodi 1994; Ouriques \& Bouzon 2000) e Bachelotia (Bornet) Kuck. ex Hamel (Magne 1976) apresentam vários cloroplastos com pirenóides terminais que convergem para um mesmo ponto na célula, dando ao conjunto um arranjo estrelado. Entretanto, os gêneros Splachnidium Greville, Scytothamnus Hooker f. \& Harvey e Stereocladum Hooker f. \& Harvey, possuem um único cloroplasto com braços que conferem a organela uma aparência estrelada, com pirenóide central perfurado por invaginações citoplasmáticas (Delépine et al. 1976; Peters \& Clayton 1998).

Com base na análise ultra-estrutural das células vegetativas, enfatizando a disposição dos cloroplastos de Ectocarpus e Hincksia de Ectocarpales, Müller \& Parodi (1994) e Ouriques \& Bouzon (2000) propuseram a 


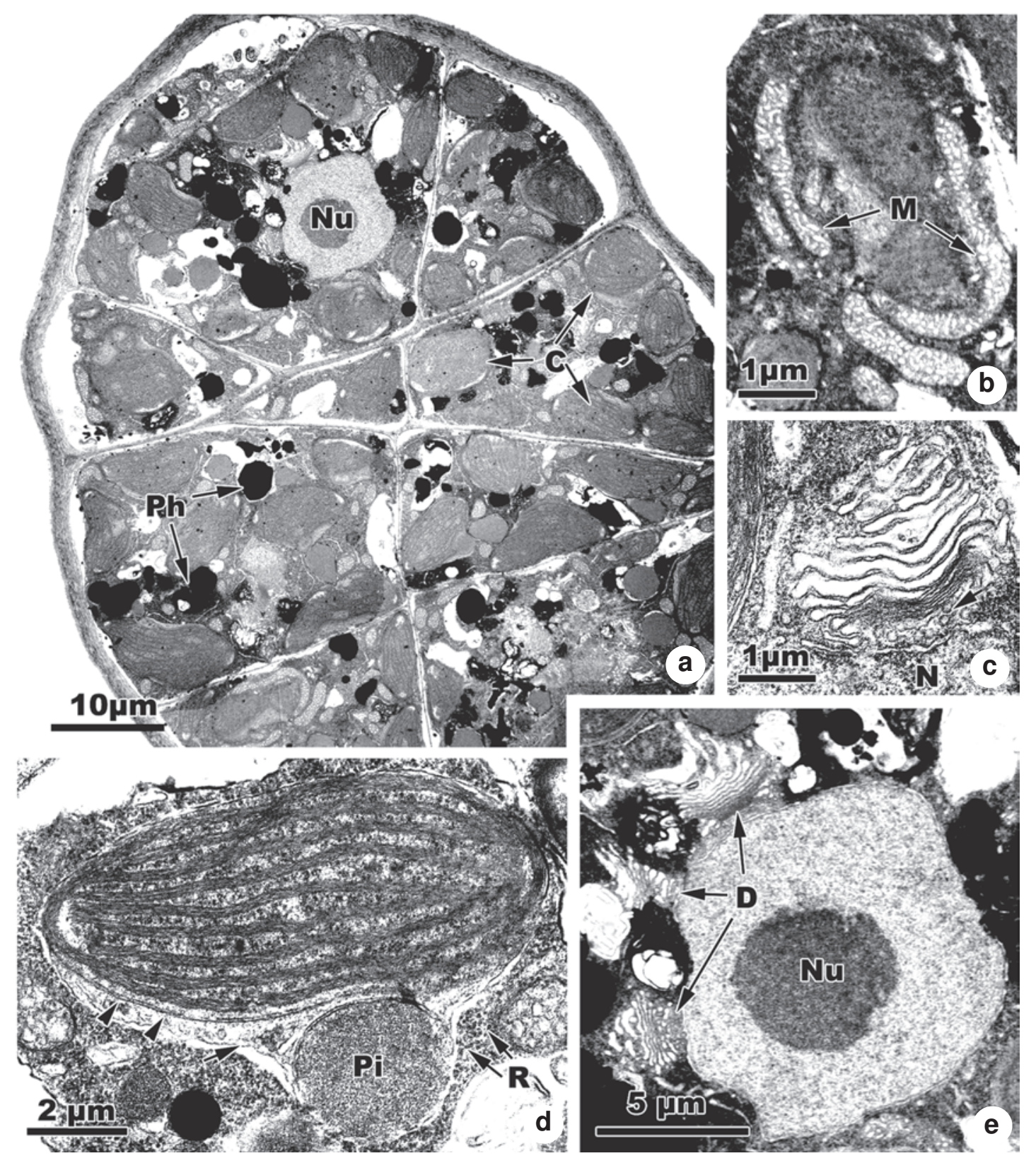

Figura 4 - Estrutura plurilocular de Hincksia mitchelliae observada no microscópio eletrônico de transmissão (MET) a. corte transversal da estrutura plurilocular mostrando que as células são compactas, e que o citoplasma é ocupado principalmente por cloroplastos $(\mathrm{C})$ e grânulos elétron-densos fisóides $(\mathrm{Ph})$. O núcleo é volumoso com nucléolo proeminente $(\mathrm{Nu})$; b. detalhe de uma porção citoplasmática mostrando algumas mitocôndrias alongadas (M); c. destaque de um dictiossomo hipertrófico com cisternas dilatadas. Observe pequenas vesículas entre a região de formação e o envelope nuclear (seta); d. detalhe do cloroplasto envolvido por uma dupla membrana (cabeças de setas), mostrando bandas de tilacóides paralelos. Note uma unidade de membrana (seta) revestindo todo o cloroplasto e o pirenóide (Pi). Numerosos ribossomos livres (R) estão presentes no citoplasma; e. detalhe do núcleo com nucléolo grande e elétron-denso $(\mathrm{Nu})$. Observe os dictiossomos (D) perinucleares. 
transferência desses gêneros para o gênero Asteronema. Nesses gêneros foi possível, ao MET e na observação de material vivo, verificar que vários cloroplastos apresentavam disposição estrelada pela convergência dos pirenóides. Esses cloroplastos foram até então, considerados não agregados, pois haviam sido observados em microscopia de luz e material fixado.

Nos cloroplastos das células vegetativas de $H$. mitchelliae foi observada a formação de um novo pirenóide em estágio de diferenciação, localizado também lateralmente. Esta característica é pouco comum dentro das Phaeophyceae, visto que, na literatura, somente duas descrições foram citadas: na célula móvel de Ectocarpus confervoides (Roth) Le Jolis, onde o novo pirenóide se originou na base do primeiro pirenóide (Evans 1960) e no zigoto de Scytosiphon lomentaria (Lyngbye) Link, onde o novo pirenóide é formado distante do primeiro (Nagasato \& Motomura 2002), semelhante ao observado em $H$. mitchelliae. Entretanto, $S$. lomentaria é considerada mais derivada em relação a $H$. mitchelliae. Vale ressaltar ainda, que essas duas descrições já citadas na literatura se referem às células reprodutivas. Segundo Nagasato \& Motomura (2002), futuros estudos são necessários a fim de esclarecer o início da formação do novo pirenóide, se a partir da base do primeiro pirenóide ou de forma independente.

No material analisado não foi observado o retículo endoplasmático envolvendo o pirenóide. Entretanto, essa característica foi verificada para outras espécies de algas pardas, como Chorda filum Stackhouse (Bouck 1965) e Asteronema rhodochortonoides (Boergesen) Müller \& Parodi (Müller \& Parodi 1994).

Uma característica que separa as ordens mais derivadas das mais primitivas é a presença de dictiossomos perinucleares como observado por Bouck (1965) em Giffordia sp. (Ectocarpales), C. filum (Laminariales) e Gunning \& Steer (1996) em Tribonema sp (Tribonematales). Entretanto, em Sphacelaria tribuloides Meneghini os dictiossomos podem ocupar uma posição perinuclear ou estarem espalhados pelo citoplasma, característica esta típica de Phaeophyceae mais avançadas taxonomicamente (Galatis et al. 1977). Nas células vegetativas de $H$. mitchelliae os dictiossomos foram observados somente na região perinuclear. A presença de dictiossomos nessa região está diretamente relacionada com a produção de vesículas que brotam da membrana externa do envelope nuclear e são incorporadas à face de formação dos dictiossomos, similar ao observado por Bouck (1965), Cole (1970) e Galatis et al. (1977). A relação funcional entre o retículo endoplasmático, incluindo o envelope nuclear, e o complexo de Golgi é evidenciada em certas células das algas (Gunning \& Steer 1996). O retículo endoplasmático e a membrana externa do envelope nuclear são freqüentemente contínuos. Neste caso, o envelope nuclear é considerado como uma cisterna especializada do retículo endoplasmático (Gunning \& Steer 1996).

As células vegetativas de $H$. mitcheliae apresentaram o núcleo interfásico com um grande nucléolo, indicando que essas células possuem uma alta atividade metabólica, resultado da intensa síntese de RNA ribossomal. Corroborando essa suposição, alguns complexos de poros são observados na membrana nuclear, sugerindo um intenso intercâmbio de material entre o núcleo e o citoplasma. Nessas células, provavelmente uma grande quantidade de ribossomos livres deve estar presente reforçando a evidência de intercâmbio núcleo-citoplasma.

As mitocôndrias estão distribuídas no citoplasma, próximas aos cloroplastos, diferindo do observado em Chorda filum, onde as mitocôndrias tendem a se posicionar ao longo da margem celular; e das observações feitas para Giffordia sp. e Fucus vesiculosus L., com mitocôndrias espalhadas por todo citoplasma (Bouck 1965). A associação com os cloroplastos deve ser resultante de uma possível interação metabólica entre estas organelas, como também observado em Sphacelaria tribuloides Meneghini (Galatis et al. 1977). 
Muitos corpos osmiofílicos correspondentes a fisóides foram vistos no citoplasma das células vegetativas de $H$. mitchelliae. Os fisóides são estruturas citoplasmáticas contendo compostos fenólicos (Clayton \& Beakes 1983; Lee 1989) muito comuns em Phaeophyceae. Essas estruturas são formadas pelo retículo endoplasmático e complexo de Golgi (Schoenwaelder \& Clayton 2000; Schoenwaelder 2002) e tipicamente elétrondensos na microscopia eletrônica de transmissão.

Nas células das estruturas pluriloculares de H. mitchelliae, os dictiossomos são hipertróficos semelhantes aos observadados em Pylaiella littoralis (L.) Kjellm. durante a citocinese (Markey \& Wilce 1975). Dictiossomos altamente ativos foram verificados no esporângio plurilocular de Ectocarpus sp. (Baker \& Evans 1973). Os resultados desse estudo indicaram que os dictiossomos são capazes de mudar de função dependendo da necessidade de cada fase do ciclo de vida da espécie. Conseqüentemente, durante a formação do esporângio, os dictiossomos do esporo em desenvolvimento produzem a matriz que é secretada dentro do esporângio. Nos últimos estádios de esporogênese e durante a fase móvel, os dictiossomos produzem numerosas vesículas contendo uma substância fibrilar responsável pela adesão dos esporos. Posteriormente, essas vesículas presentes nas células fixadas podem aparentemente contribuir para a formação de novas paredes celulares. Estas múltiplas funções desempenhadas pelos dictiossomos ocorreram também durante a ontogênese, liberação e fixação de esporos de algas vermelhas (Bouzon et al. 2005; Ouriques \& Bouzon 2005).

A organização membranar dos cloroplastos da estrutura plurilocular de $H$. mitchelliae foi semelhante ao observado nas células vegetativas. Entretanto, na superfície do cloroplasto foi possível observar uma membrana que pode ser contínua com a membrana do retículo endoplasmático rugoso como o observado em outras Phaeophyceae. Nas Ectocarpales, a camada membranosa mais externa do retículo endoplasmático rugoso é geralmente contínua com a membrana externa do envelope nuclear (Lee 1989). Em adição, o pirenóide é envolvido por uma membrane-bound cap, denominado 'saco do pirenóide' (Evans 1960).

As células da estrutura plurilocular apresentaram numerosos ribossomos livres espalhados por todo o citoplasma. A presença dessas partículas deve estar relacionada com intensa produção de proteínas que deverão ser utilizadas na biossíntese das organelas membranosas, durante o processo de fecundação e germinação.

As múltiplas células presentes na estrutura plurilocular são delimitadas por uma parede celular fina, e todas revestidas pela parede vegetativa original, semelhante ao descrito em P. littoralis (Markey \& Wilce 1975, 1976b).

O núcleo interfásico com um proeminente nucléolo é semelhante ao observado nas células vegetativas de $H$. mitchelliae, sugerindo que essas células reprodutivas possuem uma alta atividade metabólica.

Muitos corpos osmiofílicos correspondentes a fisóides foram também vistos no citoplasma das células reprodutivas, concordando com o observado por Baker \& Evans (1973) e Clayton (1984).

\section{REFERÊNCIAS BIBLIOGRÁFICAS}

Baker J. R. J. \& Evans L.V. 1973. The shipfouling alga Ectocarpus. II. Ultrastructure of the unilocular reproductive stages. Protoplasma 77: 181-189.

Bold, H. C. \& Wynne, M. J. 1985. Introduction to the Algae: structure and reproduction. 2ed. Princeton Hall, New Jersey, 719p.

Bozzola, J. B. \& Russell, L. D. 1992. Electron microscopy. Jones and Bartlett Publishers, London, 542p.

Bouck, G. B. 1965. Fine structure and organelle associations in brown algae. Journal of Cell Biology 26: 523-535.

Bouzon, Z. L.; Ouriques, L. C. \& Oliveira, E. C. 2005. Ultrastructure of tetraspore 
germination in the agar-producing seaweed Gelidium floridanum (Gelidiales, Rhodophyta). Phycologia 44: 409-415.

Clayton, M. N. 1984. An electron microscope study of gamete release and settling in the complanate from of Scytosipon (Scytosiphonaceae, Phaeophyta). Journal of Phycology 20: 276-285.

Clayton, M. N. \& Beakes, G. W. 1983. Effects of fixatives on the ultrastructure of physodes in vegetative cells of Scytosiphon lomentaria (Scytosiphonales, Pheaophyta). Journal of Phycology 19: 4-16.

Cole, K. 1970. Ultrastructural characteristics in some species in the Scytosiphonales. Phycologia 9: 275-283.

Chung, I. K K.; Ledbetter, M. C. \& Brinkhuis, B. H. 1987. Fine structure of Laminaria saccharina (L.) Lamour. The Korean Journal of Phycology 22: 147-171.

Delépine, R.; Asensi A. \& Guglielmi G. 1976. Nouveaux types d'ultrastructure plastidiale chez les Phéophycées. Phycologia 15: 425-434.

Evans, L. V. 1960. Distribution of pyrenoids among some brown algae. Journal of Cell Sciences 1: 449-454.

Galatis, B.; Katsaros, C. \& Mitrakos, K. 1977. Fine structure of vegetative cells of Sphacelaria tribuloides Menegh. (Phaeophyta, Sphacelariales) with special reference to some unusual proliferations of the plasmalemma. Phycologia 16: 139-151.

Griffiths, D. J. 1979. The pyrenoid. Botanical Review 36: 29-58.

Gunning, B. E. S. \& Steer, M. W. 1996. Plant cell biology - structure and function. Jones and Bartlett Publishers, Boston.

Herth, W. \& Schnepf, E. 1980. The fluorochrome, calcofluor white, binds oriented to structural polysacchride fibrils. Protoplasma 105: 129-133.

Hori, T. 1972. Further survey of pyrenoid distribuition in Japan brown algae. Botanical Magazine 85: 125-134.
Katsaros, C. \& Galatis, B. 1986. Ultrastructural studies on zoosporogenesis of Halopteris filicina (Sphacelariales, Phaeophyta). Phycologia 25: 358-370.

Katsaros, C. \& Pentaris, K. 1994. The ultrastructure of tetrasporogenesis in Dictyota dichotoma (Hudson) Lamourou (dictyotales, Phaeophyceae). Japanese Journal of Phycology 42: 281-290.

Kim, G. H. \& Fritz, L. 1993. Ultrastucture and cytochemistry of early spermatangial development in Antithamnion nipponicum (Ceramiaceae, Rhodophyta). Journal of Phycology 29: 797-805.

Lee, R. E. 1989. Phycology. 2ed. Cambridge University Press, Cambridge, 645p.

Magne, F. 1976. Quelques caractères cytologiques particuliers du Bachelotia antillarum (Phéophycées, Ectocarpales). Phycologia 15: 309-319.

Markey, D. R. \& Wilce, R. T. 1975. The ultrastructure of reproduction in the brown alga Pylaiella littoralis. I. Mitosis and cytokinesis in the plurilocular gametangia. Protoplasma 85: 219-241.

Markey, D. R. \& Wilce, R. T. 1976a. The ultrastructure of reproduction in the brown alga Pylaiella littoralis. II. Zoosporogenesis in the unilocular sporangia. Protoplasma. 88: 147-173.

Markey, D. R. \& Wilce, R. T. 1976b. The ultrastructure of reproduction in the brown alga Pylaiella littoralis. III. Later stages of gametogenesis in the plurilocular gametangia. Protoplasma 88: 175-186.

McCully, M. 1968. Histological studies on the genus Fucus. Protoplasma 62: 20-40.

Motomura, T., Ichimura, T. \& Melkonian, M. 1997. Coordicative of fertilization and parthenogenesis in Laminaria angustata (Laminariales, Phaeophyta). Journal of Phycology 33: 266-271.

Müller, D. G. \& Parodi, E. 1994. Asteronema rhodochortonoides nov. comb. (Ectocarpales, Phaeophyceae) - a newly 
recognized taxon with stellate chloroplast arrangement. Phycologia 33: 471-474.

Müller, D. G.; Parodi, E. \& Peters, A. F. 1998. Asterocladon lobatum gen. et sp. nov., a new brown alga with stellate chloroplast arrangement, and its systematic position judged from nuclear rDNA sequences. Phycologia 37: 425-432.

Nagasato, C. \& Motomura, T. 2002. New pyrenoid formation the brown alga, Scytosiphon lomentaria (Scytosiphonales, Phaeophyceae). Journal of Phycology 38: 800-806.

Ouriques, L. C. \& Bouzon, Z. L. 2000. Stellate chloroplast organization in Asteronema breviarticulatum comb. nov. (Ectocarpales, Phaeophyta). Phycologia 39: 267-271.

\& Bouzon, Z. L. 2005. Spore development in red algae. A case study with Nemalion helminthoides (Nemaliales, Rhodophyta). Algological Studies 116: 115-127.

Ouriques, L. C. \& Cordeiro-Marino, M. 2004. Levantamento florístico das ordens Ectocarpales, Chordariales, Scytosiphonales e Sphacelariales (Phaeophyta) do litoral do estado de Santa Catarina, Brasil. Hoehnea 31: 293-312.

Peters, A. F. \& Clayton, M. N. 1998. Molecular and morphological investigations of three brown algal genera with stellate plastids: evidence for Scytothamnales ord. nov. (Phaeophyceae). Phycologia 37: 106-113.

Rousseau, F. \& Reviers, B. 1999. Circunscription of the order Ectocarpales (Phaeophyta): bibliographical synthesis and molecular evidence. Crytogamie Algologie 20: 5-18.

Ruzin, S. E. 1999. Plant microtechnique and microscopy. Oxford University Press, Oxford, 322p.
Salgado, L. T.; Tomazetto, R.; Cinelli, L. P.; Farina, M. \& Amado Filho, G. M. 2007. The influence of brown algae alginates on phenolic compounds capability of ultraviolet radiation absorption in vitro. Brazilian Journal of Oceanography 55: 145-154.

Schoenwaelder, M. E. A. 2002. The occurrence and cellular significance of physodes in brown algae. Phycologia 41: 125-139.

Schoenwaelder, M. E. A. \& Clayton, M. N. 2000. Physodes formation in embryos of Phyllospora comosa and Hormosira banksii (Phaeophyceae). Phycologia 39: 1-9.

Sengbusch, P. V.; Mix, M.; Wachholz, I. \& Manshard, E. 1982. FITC-Labeled lectins and calcofluor white ST as probes for the investigation of the molecular architecture of cell surfaces. Studies on conjugatophycean species. Protoplasma 111: 38-52.

\& Müller, U. 1983. Distribution of glycoconjugates at algal cell surfaces as monitored by FITC-conjugates lectins. Studies on selected species from Cyanophyta, Pyrrhophyta, Raphidophyta, Euglenophyta, Chromophyta and Chlorophyta. Protoplasma 114: 103-113.

Terui, S.; Suzuki, K. \& Takahashi, H. 1995. Synchronization of chloroplast division in the ultramicroalga Cyanidioschyzon merolae (Rhodophyta) by tretment with light and aphidicolin. Journal of Phycology 31: 958-961.

Van Den Hoek, C.; Mann, D. G. \& Jahns, H. M. 1995. Algae - an introduction to phycology. Cambridge University Press, Cambridge, 623p.

Wynne, M. J. 2005. A checklist of benthic marine algae of the tropical and subtropical western Atlantic: second revision. Nova Hedwigia 129: 1-152. 